\title{
Microbiological analysis of raw milk unveiled the presence of a dairy contaminant, Corynebacterium lipophiloflavum
}

\author{
Shih-Keng Loong ${ }^{1}$, Hai-Yen Lee ${ }^{1}$, Jing-Jing Khoo $^{1}$, Fang-Shiang Lim ${ }^{1,2}$, Siti-Noraisah Ahmad-Nasrah ${ }^{2}$, \\ Adzzie-Shazleen Azman ${ }^{1}$, Chubashini Suntharalingam ${ }^{3}$, Chandrawathani Panchadcharam ${ }^{4}$, Sazaly AbuBakar ${ }^{1,2 *}$ \\ ${ }^{1}$ Tropical Infectious Diseases Research and Education Centre, Faculty of Medicine, University of Malaya, 50603 Kuala Lumpur, Malaysia, ${ }^{2}$ Department of \\ Medical Microbiology, Faculty of Medicine, University of Malaya, 50603 Kuala Lumpur, Malaysia, ${ }^{3}$ Economics and Social Science Research Centre, Malaysian \\ Agricultural Research and Development Institute (MARDI), 43400 Serdang, Malaysia, ${ }^{4}$ Department of Veterinary Services, Laboratory Diagnostics Division, \\ Wisma Tani, Federal Government Administrative Centre, 62630 Putrajaya, Malaysia
}

\section{ARTICLE INFO}

Article history:

Received on: December 21, 2018

Accepted on: January 19, 2019

Available online: September 10, 2019

Key words:

Bovine,

Food safety,

Infectious disease,

Malaysia,

Tropical

\section{ABSTRACT}

Dairy farming occupied a distinct position in agriculture since milk can be harvested every day, providing a regular source of income to the farmers. Development of the Malaysian dairy farming industry was marred by poor farm hygiene practices, leading to the proliferation of dairy-spoilage bacteria, affecting milk quality. In this study, we report the isolation and characterization of a rare Corynebacterium species from raw milk after the implementation of improved farm hygiene practices. All milking equipment, farm worker's hands and the cow's udders and teats were washed with detergent and wiped dry with clean towels before milk sample collection. Collected foremilk samples from mastitis-free cows were inoculated onto Petrifilm ${ }^{\mathrm{TM}}$ and cultured colonies were plated onto nutrient agar. Biochemical and molecular tests were performed for the identification of peculiar bacterial isolates. A unique yellow-pigmented bacteria isolate was recovered from the milk of a healthy cow after the adoption of improved farm hygiene practices. Phenotypic and genotypic characterization confirmed the milk isolate as Corynebacterium lipophiloflavum. This is the first description of C. lipophiloflavum in cow's milk and could possibly imply the influence of bovine flora in dairy contamination. The findings highlight the increasing spectrum of Corynebacterium species with potential adverse impact to the dairy industry. It is recommended to screen for C. lipophiloflavum in all milk processing facility to ensure that milk is safe for consumption and its products prepared to the highest quality and safety standards.

\section{INTRODUCTION}

Milk is a food commodity valued for its nutrition besides providing regular income for the dairy farmers [1]. In Malaysia, high local demand for dairy products resulted in the country having to rely substantially on imports [2]. The development of the local dairy production capacity began since 1974 when the Malaysian government initiated the National Dairy Development Program to reduce dependency on milk imports [2]. However, up to date, the local dairy industry still is unable to meet the demand of the growing population. Efforts are also made by local extension personnel on ensuring that while milk production capacity increases, milk quality is also maintained so as to ensure that food safety is not compromised [2]. The decrease in milk quality can be attributed to the presence of microorganisms and problems

\footnotetext{
*Corresponding Author

Sazaly Abu Bakar,

Tropical Infectious Diseases Research and Education Centre,

Faculty of Medicine, University of Malaya,

50603 Kuala Lumpur, Malaysia. Phone: +60379676670.

Email: sazaly@um.edu.my
}

with hygiene practices [3]. Improvement in farm hygiene practices has been demonstrated to reduce bacterial count and mold in raw milk [4], elevating milk quality by 2.4 times reduction of risk exposure to milk pathogens and its potential toxins. Members of the genus Corynebacterium include species that occasionally cause infection in humans and some species having been recovered solely from animals, the environment, food, water, and synthetic materials [5]. C. ulcerans, for instance, was thought to cause disease in farm workers after contact with contaminated milk or farm animals [5]. Here, we performed a microbiological analysis on raw milk after the implementation of improved farm hygiene practices to assess the impact of the initiatives. We report recovery of a rare Corynebacterium species from raw milk after the implementation of improved farm hygiene practices.

\section{MATERIALS AND METHODS}

Before the start of milking, the udders and teats of healthy dairy cows and the hands of farm workers were rinsed with $1.0 \%$ diversol and wiped dry with clean towels. Milking equipments were washed with sanitizing solution comprising of $5.4 \mathrm{~g}$ iodophor diluted in $10 \mathrm{~L}$ of 
Table 1: Biochemical and antimicrobial susceptibility profiles of Corynebacterium lipophiloflavum isolated from raw milk

\begin{tabular}{lc} 
Biochemical test & Result \\
Urea hydrolysis & + \\
Glucose fermentation & - \\
Maltose fermentation & - \\
Sucrose fermentation & Result $(\mathbf{M I C}, \boldsymbol{\mu g} / \mathbf{m L})$ \\
Antimicrobial susceptibility & $\mathrm{S}(1.0)$ \\
Cefotaxime & $\mathrm{S}(1.0)$ \\
Ceftriaxone & $\mathrm{S}(0.5)$ \\
Ciprofloxacin & $\mathrm{S}(0.5)$ \\
Erythromycin & $\mathrm{S}(0.5)$ \\
Gentamicin & $\mathrm{S}(0.12)$ \\
Meropenem & $\mathrm{S}(0.12)$ \\
Penicillin & $\mathrm{S}(1.0)$ \\
Tetracycline & $\mathrm{S}(1.0)$ \\
Vancomycin & \\
\hline
\end{tabular}

+ : Positive for the biochemical test, - : Negative for the biochemical test, S: Susceptible to the antibiotic, MIC: Minimum inhibitory concentration water and rinsed with clean water before the milking process. Foremilk specimen was collected directly from the teat after discarding the first milk. All milk specimens were collected from mastitis-free cows and inoculated onto the respective Petrifilm ${ }^{\mathrm{TM}}$ (Escherichia coli and coliform, yeast and mold, total aerobic count, Staphylococcus aureus, and Enterobacteriaceae) (3M Corporation, St. Paul, MN, United States) and enumerated [4]. Colonies on the films were then plated onto nutrient agar and incubated under aerobic conditions at $37^{\circ} \mathrm{C}$ for 24- $48 \mathrm{~h}$.

\section{RESULTS AND DISCUSSION}

One colony originating from the Enterobacteriaceae film grew unique yellow-pigmented colonies between the sizes of 0.5 and 1.0 $\mathrm{mm}$ after $48 \mathrm{~h}$ incubation. Molecular identification using 16S rDNA sequencing [6] showed that the isolate shared $99 \%$ sequence similarity to Corynebacterium lipophiloflavum DMMZ 1944 (accession no. Y09045) [Figure. 1]. Due to the close 16S rDNA similarity between different Corynebacterium strains, selected differentiating biochemical tests were performed. The Corynebacterium isolate was able to hydrolyze urea but could not ferment glucose, maltose, and sucrose [Table 1] similar to C. lipophiloflavum [7]. The exhibited biochemical

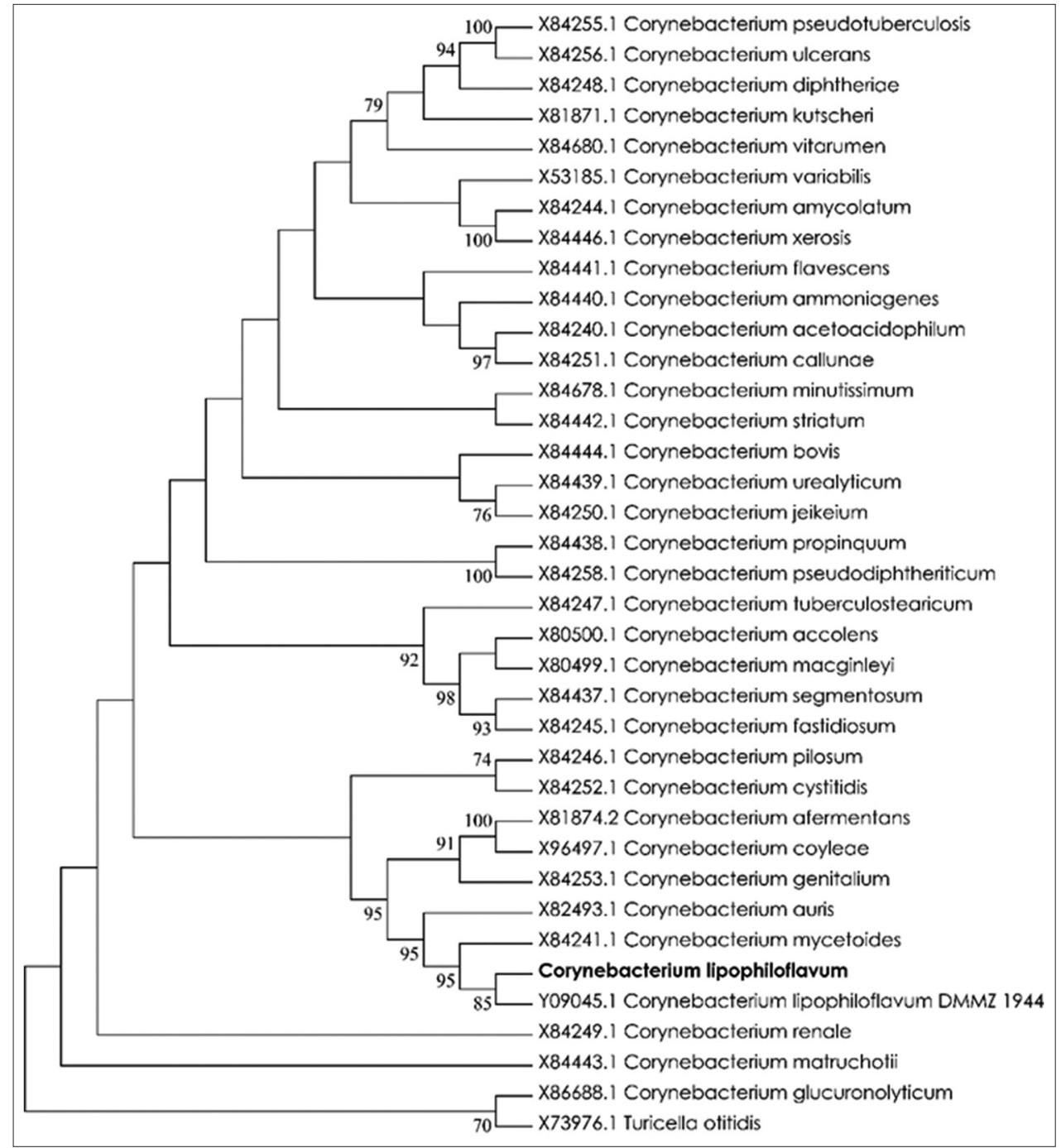

Figure 1: Neighbor-joining tree based on 16S rDNA gene of representative Corynebacterium species. Their respective accession numbers are listed before the species names. The Corynebacterium lipophiloflavum isolate in this study is indicated in bold. Number at nodes indicates bootstrap values (\%) for 1000 replicates. 
test results were different to those displayed by its closest phylogenetic relative, C. mycetoides [8] [Figure. 1], as such corroborating the $16 \mathrm{~S}$ rDNA sequencing results, confirming the isolate's identity as C. lipophiloflavum. Antimicrobial susceptibility assays performed according to the guidelines by the Clinical and Laboratory Standards Institute [9] demonstrated that the $C$. lipophiloflavum isolate was sensitive to cefotaxime, ceftriaxone, ciprofloxacin, erythromycin, gentamicin, meropenem, penicillin, tetracycline, and vancomycin [Table 1]. The minimum inhibitory concentration assays were repeated twice to verify the results. Visual inspection of the bacterial isolate after incubation in a 96 -well plate at $37^{\circ} \mathrm{C}$ for $48 \mathrm{~h}$ [10] noted that the C. lipophiloflavum isolate did not produce biofilm. Morphological characteristics of the bacterium unveiled by transmission electron microscopy [11] displayed structures similar to C. phoceense [12] and C. lactis [13] [Figure. 2]. The bacterium showed characteristic clubshaped cell and the presence of an external lipid layer.

Even though other dairy-spoilage Corynebacterium species have been found in raw milk [3], this is the description of the first C. lipophiloflavum milk isolate. It was doubtful that $C$. lipophiloflavum was derived from the environment since the sanitization protocols have been proven to be effective in reducing bacterial counts [4]. This bacterium first described from a woman with bacterial vaginosis [7], could probably resist the high hydrogen peroxide concentration environment of the vagina, akin to $C$. aurimucosum [5], and, hence, could possibly be part of the cow's vaginal flora too. There is strong possibility that $C$. lipophiloflavum was transferred from the mother to the calf during birth, comparable to the transfer of vaginal flora from mother to child during delivery [14]. This suggestion was substantiated by the antimicrobial susceptibility profile of the C. lipophiloflavum isolate, indicating that it may have emerged from an antibioticfree environment [15]. Recovery of C. lipophiloflavum even after sanitization can be explained by the transfer of endogenous bacteria during milking, which resembled the human milk bacteria colonization of breastfed neonates [16]. Although the C. lipophiloflavum isolate did not produce biofilm, it may switch from the dormant state to biofilm producer [17] on leaving the normal flora, as a result of selection and environmental pressures, further suggesting the undesirable influence of corynebacteria in dairy contamination. While C. lactis may seem harmless when it was first isolated from the cow's milk, recent studies have shown that it was also found in ticks and can cause infection

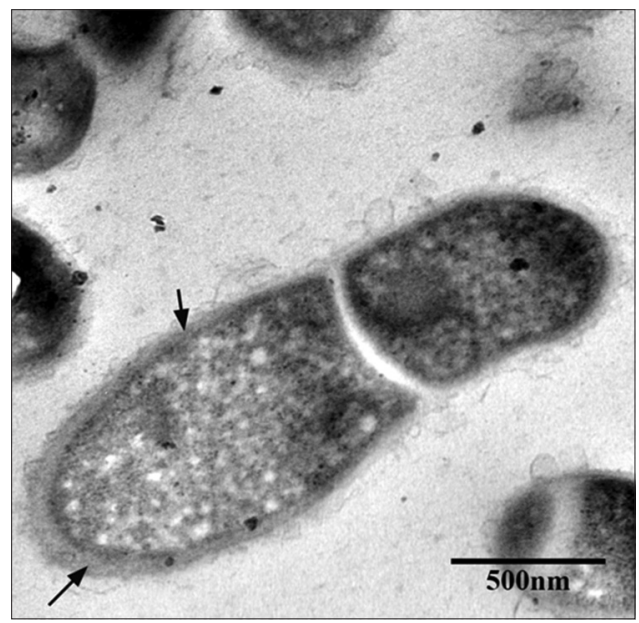

Figure 2: Morphological characteristics of Corynebacterium lipophiloflavum as displayed by transmission electron microscopy at 16,300 times magnification. Arrows show the presence of an external lipid layer. in companion animals [13]. Hence, treating C. lipophiloflavum as a harmless normal flora of the cow could have disastrous aftermath to the entire dairy supply chain. Besides, the finding of C. lipophiloflavum in the milk carries significant interest for the dairy industry. It may induce milk spoilage by expressing lipolytic and proteolytic enzymes resembling $C$. variabilis [18], besides potentially causing mastitis akin to $C$. bovis [19]. Furthermore, there are risks to the human health since C. lipophiloflavum possesses the ability to cause human infection [7].

\section{CONCLUSION}

Taken together, the findings highlight the increasing spectrum of Corynebacterium species with potential adverse impact to the dairy industry. Previous milk-associated Corynebacterium strains identified mostly to the genus level could perhaps be C. lipophiloflavum if further characterization was performed. It is recommended to screen for C. lipophiloflavum in all milk processing facility to ensure that milk is safe for consumption and its products prepared to the highest quality and safety standards.

\section{CONFLICTS OF INTEREST}

The authors declare that they have no conflicts of interest.

\section{ACKNOWLEDGMENTS}

This study was funded in parts by the University of Malaya Research University Grants (RU005-2017 and RU008-2018) and the Indian Graduates Association of Universiti Putra Malaysia.

\section{REFERENCES}

1. Moran J. Tropical Dairy Farming: Feeding Management for Small Holder Dairy Farmers in the Humid Tropics. Victoria: Landlinks Press; 2005.

2. Sim RML, Suntharalingam C. Dairy Sector in Malaysia: A Review of Policies and Programs. Food and Fertilizer Technology Center Agricultural Policy Platform; 2015. Available from: http://www. ap.fftc.agnet.org/ap_db.php?id=501. [Last accessed on 2018 Sep 12].

3. Rodrigues MX, Lima SF, Canniatti-Brazaca SG, Bicalho RC. The microbiome of bulk tank milk: Characterization and associations with somatic cell counts and bacterial count. J Dairy Sci 2017;100:2536-52.

4. Lee HY, Loong SK, Khoo JJ, Lim FS, Chai LC, Suntharalingam C, et al. Impact of hygiene intervention practices on microbial load in raw milk. J Pure Appl Microbiol 2017;11;1281-6.

5. Bernard K. The genus Corynebacterium and other medically relevant coryneform-like bacteria. J Clin Microb 2012;50:3152-8.

6. Loong SK, Che Mat Seri NA, Mahfodz NH, Ahmad Nasrah SN, Teoh BT, AbuBakar S. Emergence of Enterococcus gallinarum carrying vanA gene cluster displaying atypical phenotypes. Trop Biomed 2016;33:837-41.

7. Funke G, Hutson RA, Hilleringmann M, Heizmann WR, Collins MD. Corynebacterium lipophiloflavum sp. nov. isolated from a patient with bacterial vaginosis. FEMS Microbiol Lett 1997;150:219-24.

8. Merhej V, Falsen E, Raoult D, Roux V. Corynebacterium timonense sp. nov. and Corynebacterium massiliense sp. nov. isolated from human blood and human articular hip fluid. Int J Syst Evol Microbiol 2009;59:1953-9.

9. CLSI. Methods for Antimicrobial Dilution and Disk Susceptibility Testing of Infrequently Isolated or Fastidious bacteria. $3^{\text {rd }} \mathrm{ed}$. Wayne: Clinical and Laboratory Standards Institute; 2015.

10. Mawang CI, Lim YY, Ong KS, Muhamad A, Lee SM. Identification of $\alpha$-tocopherol as a bioactive component of Dicranopteris linearis 
with disrupting property against preformed biofilm of Staphylococcus aureus. J Appl Microbiol 2017;123:1148-59.

11. Loong SK, Tan KK, Zainal N, Phoon WH, Zain SN, Bakar S. Draft genome of the emerging pathogen, Kocuria marina, isolated from a wild urban rat. Mem Inst Oswaldo Cruz 2017;112:857-9.

12. Cresci M, Lo CI, Khelaifia S, Mouelhi D, Delerce J, Di Pinto F, et al. Corynebacterium phoceense sp. nov., strain MC1T a new bacterial species isolated from human urine. New Microbes New Infect 2016; 14:73-82.

13. Lim FS, Loong SK, Khoo JJ, Tan KK, Zainal N, Abdullah MF, et al. Identification and characterization of Corynebacterium lactis isolated from Amblyomma testudinarium of Sus scrofa in Malaysia. Syst Appl Acarol 2018;23:1838-44.

14. Dominguez-Bello MG, De Jesus-Laboy KM, Shen N, Cox LM, Amir A, Gonzalez A, et al. Partial restoration of the microbiota of cesarean-born infants via vaginal microbial transfer. Nat Med 2016;22:250-3.

15. Loong SK, Johari J, Che Mat Seri NA, Razak OA, Douadi B, Nasrah $\mathrm{SN}$, et al. Isolation and identification of an emerging pathogen, Kocuria marina, from Rattus rattus diardii. Trop Biomed 2016;33:589-93.

16. Rodríguez JM. The origin of human milk bacteria: Is there a bacterial entero-mammary pathway during late pregnancy and lactation? Adv Nutr 2014;5:779-84.

17. Marchand S, De Block J, De Jonghe V, Coorevitz A, Heyndrickx M, Herman L. Biofilm formation in milk production and processing environments; influence on milk quality and safety. Compr Rev Food Sci Food Saf 2012;11:133-47.

18. Gobbetti M, Smacchi E, Semeraro M, Fox PF, Lanciotti R, Cogan T. Purification and characterization of an extracellular proline iminopeptidase from Corynebacterium variabilis NCDO 2101. J Appl Microbiol 2001;90:449-56.

19. Taponen S, Liski E, Heikkilä AM, Pyörälä S. Factors associated with intramammary infection in dairy cows caused by coagulase-negative staphylococci, Staphylococcus aureus, Streptococcus uberis, Streptococcus dysgalactiae, Corynebacterium bovis, or Escherichia coli. J Dairy Sci 2017;100:493-503.

\section{How to cite this article:}

Loong SK, Lee HY, Khoo JJ, Lim FS, Ahmad-Nasrah SN, Azman AS,

Suntharalingam C, Panchadcharam C, AbuBakar S. Microbiological

analysis of raw milk unveiled the presence of a dairy contaminant,

Corynebacterium lipophiloflavum. J App Biol Biotech. 2019;7(05):41-44.

DOI: $10.7324 / J A B B .2019 .70507$ 